\title{
Architecture and the Dilemma of Aesthetics Towards An Alternate Definition and Approach to Architecture
}

\author{
GUNTER DITTMAR \\ University of Minnesota \\ USA
}

\begin{abstract}
The paper calls for a paradigm shift in the definition and approach to architecture to reverse the erosion of its societal relevance, and the loss of its identity as a discipline. The paper contends that this development originated with the Renaissance when architecture evolved from a craft into an art, and the pursuit of beauty became the foremost ideal: the aspect that distinguishes architecture from "mere building". Ever since, architecture has tried - and failed - to solve the dilemma of aesthetics: the integration of utility, technology and beauty. However, neither beauty, nor the question of aesthetics, are really the problem. The real issue is that architecture is, ultimately, about more than beauty or aesthetics: it is about our life and our existence; about creating a place for our being in the world. Architecture is, thus, grounded in an ontological paradigm rather than an aesthetic one. This has far-reaching, theoretical implications. The paper then proceeds to delineate some of the premises fundamental to an ontological approach to architecture, based on the notion that architecture makes possible the congruence between human and natural order, between our inner and our outer world. Beauty is present when one resonates and reveals itself through the other.
\end{abstract}

Architecture, the profession most concerned with the quality of the built environment, is increasingly becoming marginalized, partially being forced, partially escaping into the realm of pure aesthetics. Caught in the forces of the marketplace which demand efficiency and speed at minimum cost, and challenged by such competing players as developers, builders and engineering firms, the only domain where architecture still seems to be granted some degree of expertise is that of "aesthetics." This process is accelerated by an avant-garde that seeks refuge in the "freedom" of art and sculpture. Left behind is a vacuum, a lack of understanding and definition of what architecture is, and the significance it has for our daily life and existence.

It is the thesis of this paper that this development is due to the paradigm architecture has pursued since the Renaissance: the unexamined belief that what distinguishes archi- tecture from "mere building" - indeed what elevates it to an art - is the aspect of aesthetics. The pursuit and contemplation of beauty, revealed in the perfect order and harmony of the cosmos and found in the artifacts of the ancient cultures, was one of the hallmarks of the Renaissance. As an absolute ideal it permeated all the arts, from architecture to the visual arts and literature. Signifying the transition from a medieval ethos to that of the Renaissance, it endures as one of its legacies to the modern world. As art emancipated from medieval crafts and came into its own, beauty became "liberated" from its bondage to material substance, purpose or specific meaning; it evolved from an attribute to a concept, that is, to an end in itself.

The notion of beauty as an autonomous entity became formally established in architecture when Renaissance theorists, in their attempt to develop a theoretical base for the art of architecture, (re-)discovered Vitruvius ${ }^{1}$ and made the Vitruvian categories of durability, utility and beauty the central tenets of the discipline. ${ }^{2}$ Since then the Vitruvian triad has, explicitly or implicitly, constituted the universe within which architecture has defined itself. Yet, for more than five hundred years, architecture has struggled - and is still struggling - to come to grips with the question of aesthetics, that is, how to integrate the often contradictory demands of function, technology and beauty into a coherent, harmonious whole. It has proved to be a rather elusive ideal.

There are essentially three fundamental approaches to solving the "Vitruvian dilemma." All three have been explored by architecture over the recent centuries, two of them repeatedly in various differing versions and styles. The first approach could be characterized as "the architecture of beautiful form", or "architecture equals aesthetics." It views architecture as a visual art and works of architecture as aesthetic objects, to be experienced and appreciated not unlike those of painting and sculpture. With beauty as overriding goal, the emphasis is typically on the composition of space and form, and the concomitant issues of proportion, light, color, texture and materials. The utilitarian and structural dimensions of the triad are either suppressed, or totally subservient to an aspired, aesthetic ideal, formal order, or expression. 
The second approach, perhaps the most common and ubiquitous throughout recent history, defines works of architecture as essentially "functional shelter plus beauty", or "building plus aesthetics." It accepts as a given that the internal tensions of the Vitruvian triad cannot be resolved, that the aspect of beauty cannot be reconciled with the requirements of function or structure without compromising it, or relegating it to a secondary role. It, therefore, contracts the more easily integrated aspects of structure and function into one unit - "building", or functional shelter - and treats "aesthetics" as a distinct, autonomous entity, consisting of the addition of ornament, stylistic, or iconographic appliqu_. It, typically, manifests itself in richly decorated facades and interiors. More recently this approach has become known as "the architecture of the decorated shed."

The third approach is that developed by Modernism. It could, perhaps, best be described as "beautiful shelter", or "aesthetic engineering." It is unique in that it represents an entirely novel solution to the Vitruvian dilemma, one that had not been explored before in the previous centuries. Modernism, in a complete break with history and tradition, was deliberately in search of a "new architecture" and a "new aesthetic": an architecture that was not pre-ordained by solutions or styles of the past. Thus, in contrast to previous time periods, and inspired by what it perceived to be the dawning age of science and technology, Modernism tried to locate architecture in science and engineering instead of in art. Beauty was to be found in "universal truth", as manifest in the order of nature and the universe, revealed through science and realized in modern technology. It would come from "within" architecture itself rather than from "without", that is, it would be generated from within the indigenous elements of "building" - structure and function - rather than be the representation or embodiment of an external, aesthetic ideal. It would be the outcome of a rational, objective process - a universal, "scientific" formula unaffected by culture, style, taste, or personal expression. In other words, the Vitruvian triad is reduced to, essentially, just two categories: function and structure. The third beautiful form - is, by definition, already implicitly inherent in them.

After five centuries of experimentation one would expect that architecture would, by now, have found a compelling solution to the Vitruvian dilemma. Yet the search for answers continues unabated and, it appears, at an ever more frantic pace. During our own time, in less than one hundred years what previously took centuries, architecture has cycled through versions of all three of the fundamental approaches to the Vitruvian riddle: Modernism, Post-Modernism and Deconstructivism. This endless recycling demonstrates that none of the approaches is capable of yielding a lasting, satisfactory solution. A closer look at each of the approaches reveals that not only the first - "beautiful form" - but also the second and third - "shelter plus beauty" and "beautiful shelter" - end up collapsing the initial diversity of the triad into a search for beauty, a question of aesthetics. This may, ultimately, be unavoidable. According to Immanuel Kant ${ }^{4}$, the founder of Modern Aesthetics and still one of its foremost thinkers, beauty constitutes a self-referential, self-justifying presence. Its origin, telos, reason for being, lies totally within itself. As an absolute end in itself, it resists appropriation by, or subordination to, any outside purpose or factor without compromising its integrity. Beauty does not "bend" to the necessities of function and structure.

The fundamental problem for the discipline, however, is not how to integrate beauty with the demands of utility and technology, or whether aesthetics has a legitimate place in architecture. The real issue is not whether or not there is a lasting solution to the dilemma posed by this triad, but whether it addresses the right question about architecture in the first place. There can be no doubt that the Vitruvian categories of utility, durability and beauty, especially in their modern version of function, structure and form, describe significant aspects of architecture, but they are not, in and of themselves, central to the question of architecture. They are not defining elements of architecture, but general qualities we value in almost any human product, be it cars, shoes, furniture, or a pair of eyeglasses. It makes clear that the categories of the Vitruvian triad do not describe or define anything that is unique, intrinsic, or fundamental to architecture; that would distinguish buildings from other artifacts, and architecture from other fields of human endeavor.

Since time immemorial buildings have provided us with a "window" to see and understand our world." Though perhaps in ruins, and distanced from us by time, culture and place, many still speak to us with a power that cannot be explained by aesthetics alone. Each within the understanding, spirit and means of its own time is an attempt to gain a foothold in the universe, to acquire, if not physical, then at least symbolic control over our world.

Architecture, therefore, is about the reality and aspirations of our existence, the exploration of our being and our dwelling in the world. It is a means through which we not only affirm our existence, but create a place and identity for ourselves within the vast and infinite dimensions of time and space. Or, as Martin Heidegger puts it, architecture is about our "dwelling", that is, about our "being-in-the-world."

But, our world is not made up of mute objects and meaningless phenomena, nor is architecture simply the physical representation of its abstract spatio-temporal order. Through architecture, its symbolic and material structure, we enter into an active dialogue with the world around us; we appropriate it and, quite literally, "make" it into our own. Architecture, thus, is not only a means to define to ourselves our "being-in-the-world" - who and what we are - but through architecture the world reveals itself to us and comes into being.

The earth, the sky, the sun; light, gravity, materials; the daily and seasonal cycles; the interaction with our fellow human beings - these are the elements of architecture, the language that makes up the text of our dwelling, the larger order within which our existence occurs. But dwelling - 
gathering the world and make it present in a place - requires a creative and material act; it requires building. Building in this sense is more than the realization of an abstract, architectural design, or the production and technical assembly of architectural components.

Through building a wall we assert the earth, materialize gravity, and define our relationship to nature and our fellowbeings. By making a window we give life to light and space, measure to the daily and seasonal cycles, and connect to the sky and the world beyond. It is through building as an "ontological" act that we explore our dwelling, that is, establish our present place within a larger, universal order and make this order physically and symbolically manifest to ourselves.

Each work of architecture poses this question anew within the particular circumstances of its place. Each culture, time and society has to rediscover this truth within its own means and on its own terms. Architecture is, ultimately, not about abstractions, but the pursuit of the universal through the circumstantial; the timeless through the timely; the immaterial through the material.

The same applies to the nature and role of beauty in architecture. Beauty does not reside in the imagery, form, or outward appearance of a building; nor is it an end in itself. It evolves from within the context, understanding and spirit of the work itself; it is not brought to, or imposed on, design as a style, form, or aesthetic ideal. Beauty is present when a work of architecture transforms both, us and the world around us, and brings them into congruence; when our outer world resonates and reveals to us something of the mystery of our inner self, and the nature of our being.

There is little doubt that architecture is an art, but it is an art all its own. Unlike the other arts, architecture is not a reflection, representation or commentary of the world we live in, but it directly engages us with life itself. We experience - and understand - our world through architecture, not as architecture. We inhabit architecture and are active participants, not just spectators. Thus, for architecture to be relevant and meaningful, its activities and explorations must be rooted in an ontological paradigm instead of an aesthetic one.

This poses an entirely new challenge for architectural theory. For centuries, beginning already with Vitruvius, architecture was focused on defining itself through the object of its investigations, the work of architecture, - at the expense of its subject and subject matter. In the quest for answers - and ever new "aesthetics" - we seem to have lost the understanding that architecture is essentially about an eternal question: that of our being, and our dwelling, in the world.

Unless and until architecture, and architectural theory in particular, begin to concentrate on what architecture is rather than what form it should take, on developing a body of theory from within its own discipline rather than trying to define itself through other fields, be it art, engineering, the social sciences, or literary criticism, the search for architecture's identity through ever new aesthetics will continue. So will the erosion of architecture's societal relevance, and its marginalization in our everyday lives.

\section{NOTES}

1 Vitruvius, The Ten Books On Architecture (translated by Morris Hicky Morgan, Dover Public., NY, 1960)

2 cf., for instance, Leon Battista Alberti's theoretical treatise De Re Aedificatoria, first published in Florence, 1485, which was structured around the Vitruvian categories

3 cf. Robert Venturi, Denise Scott Brown, Steven Izenour, Learning from Las Vegas, revised edition, p.87 (The MIT Press, Cambridge, Mass., 1985)

${ }^{4}$ Immanuel Kant, Critique of Judgment, first published 1790; cf. particularly the First Division, First Book, Third Moment

5 Some of this and the following material was published earlier in Dwelling and Building, Architecture Minnesota, Vol.17, No.1, January/February 1991

${ }^{6} \mathrm{cf}$., for instance, Martin Heidegger, Building Dwelling Thinking (translation by Albert Hofstadter in Poetry, Language, Thought; Harper \& Row, 1975) 